\title{
Some reflections on the tax simplification proposal and the implication for self-invested personal pensions \\ Received: 21st May, 2003
}

\section{John Moret}

is Executive Chairman of Personal Pension Management Limited (PPML) and is Director of Pensions Strategy for its parent company, Winterthur Life UK Limited. PPML is one of the leading administrators of self-invested personal pensions (SIPPs). John has been involved with SIPPs since they were launched in the UK in 1990.

Abstract The Treasury and Inland Revenue proposals on pensions tax simplification in the UK are wide-ranging and potentially will have a major impact on all parts of the pension savings market. SIPPs have been one of the fastest growing sectors of this market in recent years with total assets now estimated to be over £20bn, reflecting the collective investments of around 80,000 individual SIPP investors.

Keywords: SIPPs; lifetime limit; annual limit; 401(k) plans; income drawdown; prudential investment standards; SSAS; employer-related investments; FSMA; CP179

\section{Introduction}

This paper looks at some of the key changes proposed in the Treasury consultative document and their potential impact on the SIPP market.

\section{Proposals}

The government's proposals on simplifying the taxation of pensions have received wide acclaim. Unlike previous changes to the taxation of pensions, a clean break is proposed. If implemented, all pension saving would follow a single

\section{John Moret}

Personal Pension

Management Ltd, 24-27 Barnac Business Centre, Blakey Road, Salisbury, Wiltshire SP1 2LP, UK.

Tel: +44 (0)1722 437 352; e-mail:

john.moret@ppml.co.uk set of rules which will apply to all types of pension scheme and there would be a single set of 'simple rules' applicable to the conversion of the accumulated savings into benefits.

Although pension rights built up before implementation would be respected, the eight different sets of tax rules currently in place would be replaced with a new set of transparent rules, with the aim of making pensions easier to understand and simpler to administer. The hope is that this will greatly increase choice and flexibility for individuals, employers and pension providers.

At the time of writing, the closing date for comments on the proposals has passed and it would seem that the Inland Revenue is going to be busy as it has over 500 responses to consider. It appears that a second set of more detailed proposals can be expected over the summer, which will reflect at least some of the comments received on the initial document.

This paper focuses on some of the key elements of the proposals and the 
potential impact on one part of the pensions market place - self invested personal pensions (SIPPs). The paper is based on some of the suggestions that Winterthur Life included in its response to the Revenue and it also draws on some of the proposals from the SIPP Provider Group (SPG).

Four main areas of potential reform are discussed:

— the light touch controls on pension saving;

— the reforms on emerging benefits;

- prudential investment standards; and

— the regulatory framework for establishing and administering a pension scheme.

The proposals on the simplification of pensions taxation are an integral part of the government's broader objectives for tackling the root causes of inadequate pension saving in the UK. When considering the proposals it is important to take a holistic view, not only of the long-term pension savings market but also the shorter-term alternatives that currently exist. Striking the right balance is essential and will include the terms on which shorter-term savings might be rolled over into long-term pension savings.

\section{The light touch controls on pension saving}

Much of the attention of those close to the SIPP and related markets has focussed on the lifetime limit. The author agrees with the principle of a lifetime limit that starts at a level broadly equivalent to the fund required to purchase a pension of two-thirds of the earnings cap. The SPG in its response has suggested that the current proposed limit of $f 1.4 \mathrm{~m}$ is too low. Based on the earnings cap of $£ 99,000$ it has calculated the current market-rate cost of securing a two-thirds pension to be just over $\mathcal{E} 1.9$ million and has suggested that a figure of $f^{2}$ million would be a more appropriate limit.

It will be interesting to see if this suggestion gets a sympathetic reception, but in any event the more critical issues are to ensure that pre A-day (the date the new regulations come into force) benefits are suitably protected and that the indexation of the lifetime limit ensures that the real value of the purchasing power of the limit is maintained. To achieve suitable protection of pre A-day limits, Winterthur's has suggested in its response to the Revenue, that a limit of $f_{1} 1 \mathrm{~m}$ (based on the current proposed limit of $\mathcal{E}^{1.4 \mathrm{~m})}$ is set for registering pre A-day benefits. This should provide an acceptable balance between equity and practicality, providing protection for individuals with funds above this limit should they experience better than average investment performance for a period of years post-A-day.

It was also suggested that the 'protected fund' is recorded as a percentage of the lifetime limit. For example, a fund of $f 1.19 \mathrm{~m}$ could represent 85 per cent of $\mathcal{f} 1.4 \mathrm{~m}$ allowing the individual to contribute and accumulate funds to take up the remaining 15 per cent. Only funds (excluding the ring fenced funds) that exceeded 15 per cent of the lifetime limit would be subject to a recovery charge.

Winterthur's response to the Revenue also suggested that the government could take the even bolder step of doing away with any annual limit. The consultation document states that the purpose of the annual limit of $£ 200,000$ is to guard against tax leakage. Whilst government concern is understandable, the imposition of an 
annual limit appears to add complications for individual savers, through additional obligations in their annual tax returns, and for scheme administrators, through additional disclosure of information, with no guarantee of effective control.

The government may wish to introduce a limit for two or three years to 'test the water' but ultimately the aim should be to abolish any annual limit. It is also reasonable to consider increasing the $f^{3}, 600$ annual limit on personal contributions (without reference to earnings) and in Winterthur's response a higher figure (initially of $£ 5,000)$ was suggested. This bears more relation to the lifetime limit.

Another key ingredient to the success of these proposals should be the ability to allow consolidated pension pots from previous pension scheme memberships to be paid in as a net contribution without being subject to the earnings test. This is similar to the American Individual Retirement Accounts and the Australian 'roll over' products, the concept of which seems to be worthy of further study.

\section{Reforms on emerging benefits}

Many of the proposals on the benefits that can be drawn from pension savings are to be welcomed. Winterthur proposed certain modifications which complemented the need for simplicity, flexibility and encouragement for pension savings, as there is an overriding concern that the significantly increased range of options on retirement will create confusion amongst prospective pensioners.

The author believes that one of the major obstacles to achieving a long-term savings culture is the inability, under the current rules, to access the accumulated pension savings at any time regardless of the need. In the USA, 401(k) plans provide access in certain circumstances through a loan. However, Winterthur put forward a more radical proposal to tackle this issue, which is imperative if more people are to be encouraged to save for retirement using pensions vehicles.

It is suggested that under the new regime, accumulated tax-free cash can be taken at any time in isolation of the remaining 75 per cent of the fund. Although this would potentially reduce the funds available at retirement, this facility would be attractive to individuals, would encourage pensions savings and would be broadly tax-neutral.

The government proposals allowing greater flexibility in the nature and pattern of income payments, particularly after the age of 75 are to be welcomed. However, as they stand, the proposals to extend income drawdown beyond 75 will provide real difficulties for providers and will not encourage pension provision.

The current proposals provide that on the death of the member a lump sum may be paid based on the initial income drawdown fund, less payments made, less a tax charge. After 75, no lump sum is available, although income can be paid to a surviving spouse of dependant. Where there is no dependent it appears that the remaining fund will be retained by the provider or the occupational scheme. This is unsatisfactory and unjustified.

The only reasonable way to deal with this is to treat income drawdown death benefits after 75 in broadly the same way as pre-75 death benefits, but with amendments to the tax charge. Similar proposals would also apply to the lump sum death benefit payable on death after 75 for value protected annuities.

These issues can be addressed by allowing a lump sum to be paid on 
death, irrespective of age for both annuities and income drawdown, with the following provisions.

- For an annuity, the lump sum payable would represent the purchase price less annuity payments made less a tax charge. For income drawdown, the lump sum would be the fund on death less a tax charge.

- The tax charge should be graduated depending on the size of the lump sum payable. It could be 20 per cent on the first $\mathcal{E} 100,000$, then 35 per cent on the next $\mathcal{E} 400,000$ and 50 per cent on the balance of the fund over $f^{5} 500,000$.

- The tax thresholds referred to above should be indexed in line with the lifetime limit.

This proposal would provide several advantages. It will:

- benefit the mass market and ensure that there is no tax advantage for those with large funds,

— be broadly tax neutral,

- avoid the 'cliff edge' approach of the current proposals, where the death benefit position is different pre- and post-75 for both annuities and income drawdown.

There are several other points to make.

- The proposed minimum income drawdown limit of $f 1$ is illogical and administratively inconvenient. It would be simpler to scrap any minimum requirement.

- There is no obvious reason why the maximum guaranteed annuity period is ten years.

- The maximum annual income should be derived from Government Actuary's Department rates at present, rather than open market rates as suggested. The market rate alternative could lead to daily fluctuations, requires additional unnecessary administrative effort and has the potential to confuse the investor.

There is no strong rationale for removing the flexibility of allowing individuals to retire from the age of 50 , and increasing the minimum age at which pension benefits can be drawn to 55. If the argument is based on increasing longevity then there is also a similar and logical argument for increasing the latest date by which pension income must be taken from 75 to 80 .

\section{Prudential investment standards}

A big area of discussion for SIPPs is the proposal to apply the same investment rules to all types of pension scheme whether large or small. It is essential that the current opportunities to invest directly into equity, gilts, property and other sectors - along with collective investments - are maintained. This flexibility is one of the main reasons for the staggering growth in SIPPs over the past 13 years and there is no justification for curtailing the opportunity on the back of 'simplification'.

However, it seems reasonable that these opportunities should be available as an extension to the more traditional type of individual pension arrangement rather than as a special class of investment. Historically, the overhead in monitoring certain small self-administered scheme (SSAS) investments has been high and it seems desirable to streamline the administration of these more flexible pension investment arrangements whilst ensuring the appeal is not curtailed. This might mean the end of SSASs - and perhaps SIPPs - as we know them today, to be replaced by a more flexible 
pensions savings vehicle where the breadth of investment opportunities is dictated by the provider.

For reasons of financial probity, it seems sensible to limit investment in the employing company whether through shares or loans. The proposed 5 per cent limit on employing company shares seems reasonable. If proposals regarding access to tax-free cash are accepted, then a 25 per cent limit on loans to employers would be reasonable.

It is imperative that any new rules on investment should not restrict the appeal of property investment. The risks of investing in an employer's or owner's property are very different from those associated with equity or loan investment. There is no reason why this investment could not be made via transfer of ownership of an existing property as opposed to the current restrictions that apply to SIPPs which only permit investment in newly acquired property. It is very reasonable in these deliberations to consider widening the allowable investments to other areas such as residential property, provided there are adequate controls in place.

In their submission, the SPG have also recommended that the existing borrowing limits on SIPPs should be retained. They have also suggested that a number of the unintended restrictions introduced by the SIPP investment regulations in 2001 should be removed.

The SPG also recommended lifting the prohibition on acquiring property after the later of age 65 or the date income drawdown commences and that borrowing to finance purchase of commercial property after income drawdown commences should be permitted. Both these current restrictions are unnecessary complications and the case for change here is clear.

\section{The regulatory framework for establishing and administering a pension scheme}

There is little information in the proposals on the governance requirements for this new regime - the assumption must be that there is no intention to disturb the current basis of trust law. However, it is important to consider the future legal and regulatory framework, particularly for individual pension schemes - including SIPPs in the future.

It seems that the governance requirements for stakeholder pensions may be helpful when designing a blueprint for the future. This provides for either trust-based schemes or contract-based schemes. Both options appear likely to be required in the future, depending on the nature of the provider.

Currently, the position on personal pensions is confused - particularly in the case of SIPPs - where there are a variety of structures frequently involving different organisations as provider, trustee, scheme administrator and day-to-day administrator. This is an opportunity to rationalise this structure and achieve much greater transparency.

It is also opportune to review the regulatory framework for individual pension schemes. Currently there is a disparity in the arrangements that exist for occupational schemes and personal pension schemes and between trust-based and contract-based schemes. This needs overhauling to ensure there is clarity around roles and responsibilities in the context of the Financial Services and Markets Act (FSMA). It is imperative to strike the right balance between encouraging employers to promote their own employer-sponsored schemes and protecting the interests of members and investors.

It is entirely reasonable to consider 
extending the organisations and businesses that can provide pension schemes in the future. However, it is essential that due consideration is given to the regulatory and financial adequacy requirements of these organisations so they provide the requisite level of consumer protection.

There may well be merit in introducing a new type or types of permitted activities under the FSMA to cover areas such as pensions administration. Currently, unlike other investments, there are no specific FSMA requirements or standards for pension scheme administration.

The recently issued Financial Services Authority (FSA) consultative paper 'CP179: The Authorisation manual Draft perimeter guidance on activities related to pensions schemes' illustrates very clearly the complex minefield that currently exists - and the illogicality of many of the provisions. The paper runs to 62 pages and is very wide-ranging covering both occupational and personal pension schemes and the range of activities associated with the running of these schemes and the related investment administration activities. At the time of writing the consultation period for responding to this document is still open. Potentially it raises many questions, not only for SIPP providers and administrators, but particularly for those involved with SSASs. The current regulatory regime for SIPPs is unsatisfactory, with the need for authorisation and the extent of regulated activities being very unclear. Most SIPP administrators and trustees remain unregulated and - at the very least they need to look very closely at the implications of the proposals in this document.

\section{Conclusion}

The implications of the tax simplification proposals are profound. Assuming they are implemented without major amendment they will impact the activities of administrators and trustees of all pension schemes. SIPPs are no exception, but there is the added complication of the lack of conformity in legal structure and in the regulatory regime under the FSMA. Depending on the outcome of the consultation process on both the tax simplification and FSA proposals - together with the social policy setting provisions of the DWP Green Paper - there could be a major boost to the pension savings industry in the UK. If so, SIPPs appear well placed to share in that growth - giving further momentum to what has already been an exceptional period of consistent growth ever since the 'concept' of a SIPP was introduced in 1990. 